\title{
An Experimental Evaluation of the Serial Cost Sharing Rule*
}

\author{
Laura Razzolini ${ }^{\dagger \ddagger}$, Michael Reksulak ${ }^{\dagger}$, and Robert Dorsey ${ }^{\dagger \dagger}$ \\ $\dagger$ University of Mississippi, University, MS 38677 \\ $\ddagger$ National Science Foundation \\ $\dagger^{\dagger}$ FNC, Inc.
}

December 1999

Revised July 2002

\begin{abstract}
This paper proposes an experimental test of the strategic equilibrium properties of the serial cost sharing rule originally proposed by Shenker (1990) and then analyzed by Moulin and Shenker (1992). We report measure of the performance and efficiency of the serial mechanism by comparing the choices and values attained by the subjects to the expected first best allocations. Experimental evidence shows that, while some learning is needed, the serial mechanism leads to almost efficient allocations.
\end{abstract}

${ }^{*}$ We thank Yan Chen, Herve Moulin and seminar participants at the University of Siena and at Virginia Tech for discussion and comments. Financial support from the Office of Naval Research, and the Hearin Foundation is gratefully acknowledged. Laura Razzolini also acknowledges financial support from the National Science Foundation, grant SBR-9973731. Any remaining errors are ours. The views expressed in this paper are the authors and do not necessarily represent those of the National Science Foundation. Address: Department of Economics, The University of Mississippi, University, MS 38677. Fax: (662) 915-5821. Email: laura@olemiss.edu. 


\section{Introduction}

Many organizations face a continual challenge of allocating common resources among its members. For instance, resources such as supercomputers, secretarial support, observatories, lab facilities, university classrooms, etc., are shared by many members within an organization. When the supply of the shared good is not limited, the problem of its allocation reduces to searching for a mechanism that allows sharing the cost of the service among the users in a way that is just and fair. The constraints placed on the design process can be numerous. For instance, incentive compatibility (i.e., truthful preference reporting is a dominant strategy for each user); budget balancing; anonymity (i.e., the name of the user does not matter); monotonicity (i.e., cost shares increase when users demand more output); and nonenvy (i.e., no one would prefer the allocation of another agent). This amounts to identifying a cost sharing mechanism which distributes the service and allocates the cost among the users. The "serial cost sharing rule" is a possible mechanism to allocate a shared resource among its users and share the corresponding cost.

The serial cost sharing rule was originally proposed by Shenker (1990) and then analyzed by Moulin and Shenker (1992) in the context of costs and surplus sharing with complete information. The mechanism can be characterized by four properties: unique Nash equilibrium at all preference profiles, anonymity, monotonicity and smoothness (i.e., the individual cost shares are continuously differentiable function of the output demand). When agents requesting quantities are endowed with convex, continuous and monotonic preferences, then the game induced by the serial cost sharing rule is dominance-solvable and the unique Nash equilibrium is robust to coalitions deviations provided that agents cannot transfer output (see Moulin and Shenker (1992) and Deb and Razzolini (1999) for a proof). The applicability of the rule, however, still needs to be extensively verified. This motivates the study reported in this paper.

We have constructed a series of experiments to evaluate the performance of the serial mechanism and its strategic equilibrium properties. We studied the subjects' reactions to realistic incentives in situations when a common resource needs to be shared and paid for. The subjects were asked to make decisions about the quantity of the common good they desire to acquire, given that costs are shared according to the serial mechanism. This study reports measure of the performance and efficiency of the serial cost sharing rule by comparing the choices and payoffs attained by the subjects to 
the expected maximum possible values, under two different treatments: a sequential and a simultaneous-move treatment. The sequential treatment corresponds to the implementation of the rule with successive elimination of dominated strategies, while the simultaneous-move treatment corresponds to the normal form of the game.

Few other experimental studies of the serial cost sharing rule are available in the literature. One is by Y. Chen (forthcoming). She studies the serial and the average cost sharing rules under complete and limited information. She found that the two mechanisms are statistically undistinguishable under complete information. However, under limited information the serial rule performs better than the average cost pricing rule in terms both of equilbrium play and system efficiency. Her testing of the serial cost sharing rule involves only two subjects at the time, and it is framed as a learning process. The testing of the rule when more than two subjects are involved raises challenging experimental design questions. A preliminary study by Chen and Razzolini (2002) compares the two rules with twelve players of four different types under various information settings. The objective is to assess the performance of the two mechanisms and to study how human subjects learn and converge to the Nash equilibrium outcome under different settings. Finally a paper by Gailmard and Palfrey (2000) compares the serial rule with voluntary cost sharing mechanisms with proportionate rebate and with no rebates. They consider the case of an excludable binary public good, while the other studies allow for multiple levels of provision of a private good.

In this paper we focus on the strategic properties of the serial cost sharing rule, by testing the mechanism under a sequential and a simultaneous-move treatment. We investigate the performance of the serial rule with four different types of agents under limited information (i.e., the human players know only their own cost share and total payoff, but have no information on their opponents' payoff structure). In order to isolate and characterize the individual subjects' strategic behavior, we have designed the experiment so that each human player interacts with three computerized agents.

The paper is organized as follows: Section 2 describes the serial cost sharing rule and reviews its normative properties. Section 3 describes the experimental design, Section 4 reports the results of the experiment, and Section 5 concludes. 


\section{The Serial Cost Sharing Rule}

Consider a set of potential users of a shared resource, $N=\{1,2, \cdots, i, \cdots, n\}$. Let $q_{i}$ be the quantity of the common resource that each users wish to consume. Let $C(q)$ be the cost function for producing $q$ units of output. We assume that $C$ is strictly convex, nondecreasing on $\Re_{+}$and $C(0)=0$. A cost sharing mechanism is a mapping $\xi$ associating to each cost function $C$ and a vector of individual demands $q=\left(q_{1}, \cdots, q_{n}\right) \in \Re_{+}^{n}$ a vector of cost shares $\left(x_{1}, \cdots, x_{n}\right) \in \Re_{+}^{n}$ such that:

$$
x_{i}=\xi_{i}(C, q) \quad \forall i \in N \quad \text { and } \quad \sum_{i} x_{i}=C\left(\sum_{i} q_{i}\right) \quad\left(x_{i} \geq 0\right) .
$$

The serial cost sharing rule can be described as follows: The individuals report their individual demands $\left(q_{1}, \cdots, q_{n}\right)$. Given such demands, order them in increasing order: $q_{1} \leq q_{2} \leq \cdots \leq q_{n}$. Then assign to the first individual (i.e., the one with the lowest demand) the following cost share:

$$
x_{1}=\xi_{1}(C, q)=\frac{C\left(n q_{1}\right)}{n} .
$$

That is, agent 1 pays $1 / n$th of the cost of producing $n$ times the quantity she demands, $n q_{1}$, or his unanimity bound.

Agent 2 (i.e., the one with the second lowest demand) is then charged agents 1's cost share plus $1 /(n-1)$ th of the incremental cost from $n q_{1}$ to $(n-1) q_{2}+q_{1}$ :

$$
x_{2}=\xi_{2}(C, q)=\frac{C\left(n q_{1}\right)}{n}+\frac{C\left(q_{1}+(n-1) q_{2}\right)-C\left(n q_{1}\right)}{n-1} .
$$

And so on. To write a general formula, it is useful to redefine quantities in the following way, still assuming without loss of generality, $q_{1} \leq q_{2} \leq \cdots \leq$ $q_{n}$ :

$$
\begin{gathered}
q^{1}=n q_{1}, \quad q^{2}=(n-1) q_{2}+q_{1}, \quad q^{3}=(n-2) q_{3}+q_{2}+q_{1}, \cdots \\
q^{i}=(n-i+1) q_{i}+\sum_{j=1}^{i-1} q_{j}, \quad \cdots, \quad q^{n}=\sum_{j=1}^{n} q_{j} .
\end{gathered}
$$

The serial cost sharing rule is, then, defined as follows:

$$
x_{1}^{S}=\xi_{1}(C, q)=\frac{C\left(q^{1}\right)}{n}, \quad x_{2}^{S}=\xi_{2}(C, q)=\frac{C\left(q^{2}\right)}{n-1}-\frac{C\left(q^{1}\right)}{n(n-1)},
$$




$$
x_{3}^{S}=\xi_{3}(C, q)=\frac{C\left(q_{3}\right)}{n-2}-\frac{C\left(q_{2}\right)}{(n-1)(n-2)}-\frac{C\left(q_{1}\right)}{n(n-1)} ;
$$

repeating the argument:

$$
x_{i}^{S}=\xi_{i}(C, q)=\frac{C\left(q^{i}\right)}{n-i+1}-\sum_{j=1}^{i-1} \frac{C\left(q^{j}\right)}{(n+1-j)(n-j)} \forall i=1, \cdots, n .
$$

The serial cost sharing rule satisfies several normative properties. The rule is monotonic: that is, the individual cost shares are nondecreasing in $q_{i}$. It satisfies fair ranking: if $q_{i} \geq q_{j}$ then $x_{i}(C, q) \geq x_{j}(C, q)$. The rule satisfies anonymity: the name of the agents does not matter, and smoothness: the cost shares are continuously differentiable functions of the vector of demands. Each cost share is bounded from above by the unanimity bound $x_{i}(C, q) \leq \frac{C\left(n q_{i}\right)}{n}$ and from below by the stand alone cost share $x_{i}(C, q) \geq C\left(q_{i}\right)$.

Finally, the rule possesses a strong strategic property. Assuming that each user derives utility or profit from $q_{i}$, and assuming that each has a bounded endowment of resources $M_{i}$, then preferences can be defined on $\left[0, M_{i}\right] \times \Re_{+}$. They are nondecreasing in $q_{i}$, nonincreasing in $x_{i}$, nowhere locally satiated, continuous, convex and representable by a general utility function $U^{i}\left(q_{i}, x_{i}\right)$. Notice that special cases, such as a quasi-linear utility function $\left(U^{i}\left(q_{i}, x_{i}\right)=u^{i}\left(q_{i}\right)-x_{i}\right)$, are included under this general utility specification. Consider in this context the normal form game where each agent chooses strategically her output demand and the cost shares are calculated according to the serial formula described above. Such a game has a unique Nash equilibrium at all preference profiles, as Moulin and Shenker (1992) show. The game is dominance solvable and noncooperative behavior is unambiguously optimal.

\section{$3 \quad$ Experimental Design}

To experimentally test the performance and applicability of the serial cost sharing rule, we have designed an experiment to study the subjects' behavior when asked to choose strategically output demand, given that the cost is allocated according to the serial cost sharing formula. We have considered the simple case where individual demanders have continuous quasi-linear preferences of the form $U^{i}=\alpha_{i} q_{i}-x_{i}$, where $\alpha_{i}$ is the marginal willingness to pay for the shared good, $q_{i}$ is the chosen quantity, and $x_{i}$ the cost share 
they must pay to get the corresponding quantity. We have assumed a convex cost function of the form $C(q)=\frac{q^{2}}{2}$, where $q$ is the total quantity requested by all agents.

The experimental design is such that each subject is called to share the good with (or plays against) three computerized players. The subjects are told that the computerized players always choose the quantity that earns the highest possible return or maximizes utility. Every player, human or computerized, is characterized by a different preference parameter $\alpha_{i}$. The higher $\alpha_{i}$, the more the player likes the good and the higher her optimal demand should be. With general parameters and assuming $\alpha_{1}<\alpha_{2}<\alpha_{3}<$ $\alpha_{4}$, the unique, dominance-solvable Nash for each player is characterized by:

$q_{1}=\frac{\alpha_{1}}{4}, q_{2}=\frac{\alpha_{2}}{3}-\frac{\alpha_{1}}{12}, q_{3}=\frac{\alpha_{3}}{2}-\frac{\alpha_{2}}{6}-\frac{\alpha_{1}}{12}$, and $q_{4}=\alpha_{4}-\frac{\alpha_{3}}{2}-\frac{\alpha_{2}}{6}-\frac{\alpha_{1}}{12}$.

We conducted the experiment under two different treatments. In the first treatment, the serial rule is implemented sequentially. That is, with four players, the allocation of quantities and cost shares to players is implemented in four successive rounds, as if the game was played sequentially (this corresponds to the implementation of the mechanism in dominant strategies). In the first round, the cost share assigned to every player $i$ requesting a quantity is its unanimity bound:

$$
\frac{C\left(n q_{i}\right)}{n} \text { or } \quad \frac{C\left(4 q_{i}\right)}{4}=2 q_{i}^{2},
$$

where $q_{i}$ is the quantity requested. Each player will, therefore, demand the quantity $\left(q_{i}\right)$ such that

$$
\operatorname{Max}_{q_{i} \geq 0} U^{i}\left(q_{i}, \frac{C\left(4 q_{i}\right)}{4}\right)=\alpha q_{i}-2 q_{i}^{2}
$$

Out of the four quantities requested, only the lowest demand will be satisfied and the corresponding payoff $\left(\alpha q_{i}-2 q_{i}^{2}\right)$ will be paid. Let $q_{1}^{*}$ be the quantity requested and assigned in the first round. Observe that $q_{1}^{*}$ is actually the strategy that guarantees the highest utility level for player 1 .

In the second round, consider the reduced game with three players left. The cost share assigned to every player is

$$
\frac{C\left(4 q_{1}^{*}\right)}{4}+\frac{C\left(q_{1}^{*}+3 q_{i}\right)-C\left(4 q_{1}^{*}\right)}{3}=\frac{1}{2} q_{1}^{* 2}-\left(q_{1}^{*} q_{i}+9 q^{2}\right),
$$


where $q_{i}$ again is the quantity reported by each player in the second round, not smaller than $q_{1}^{*}{ }^{1}$ Given this cost share, each of the three players will request a quantity to maximize utility

$\operatorname{Max}_{q_{i} \geq q_{1}^{*}} U^{i}\left(q_{i}, \frac{C\left(4 q_{1}^{*}\right)}{4}+\frac{C\left(q_{1}^{*}+3 q_{i}\right)-C\left(4 q_{1}^{*}\right)}{3}\right)=\alpha_{i} q_{i}-\frac{1}{2} q_{1}^{* 2}-\left(q_{1}^{*} q_{i}+9 q^{2}\right)$.

Out of the three quantities requested, again only the lowest quantity, say $q_{2}^{*}$, will be assigned, and the corresponding payoff will be paid. This process continues, until all players have been assigned a quantity and received a payoff. This algorithm, as Moulin and Shencker observe (1992, page 1019), corresponds to the successive elimination of dominated strategies and the game induced by the serial rule converges to a unique strong Nash equilibrium. In this multi-rounds game, every player has a dominant strategy: to compute truthfully at each round the solution of the corresponding optimization problem.

In the second treatment, the experiment is implemented as a normal form or a simultaneous move game. That is, the four players simultaneously request quantities, the program orders them and charges to each player the corresponding cost share. Since three of the players are computerized and always play their Nash equilibrium strategy, it is feasible to implement the mechanism as a one shot game, and the choice for the human subject is, incentive-wise, equivalent to the one that they are called to make when the game is implemented sequentially.

All experiments have been conducted at the Mississippi Experimental Research Laboratory at the University of Mississippi. Ninety-five subjects participated in the experiments. They were students recruited from upper division and graduate classes in the School of Business. Each student was recruited to participate in two sessions approximately one week apart. The first session was a training session in which the subjects familiarized themselves with the program. Subjectes were paid a $\$ 10$ show-up fee. In both sessions they were asked to go through 30 periods of experiment. In the second session subjects were paid a $\$ 5$ show-up fee in addition to their earnings

\footnotetext{
${ }^{1}$ In order to preserve the nonmanipulability of the serial cost sharing rule, notice the specific constraint on the quantities requested after the first round (see Moulin and Shenker 1992, page 1028). That is, in each round after the first, the quantities that subjects are permitted to choose cannot be smaller than the quantity assigned in the previous round. This constraint is very similar to the practice followed in standard English auctions, where bidders, once they dropped out of the auction at a lower price are not allowed to reenter the bidding process at a higher price.
} 
from the experiment. Total earnings ranged from a low of $\$ 5$ to a high of $\$ 20$, the average earnings were $\$ 17.85$. A copy of the instructions is provided in the Appendix. The computer screen presented to the subject is shown in Figure 1. On the screen, subjects can select and change the quantity desired by clicking on the arrows. For each quantity selected, the screen shows the potential earnings, cost and profit.

In each of the 30 periods, the players, both computerized and human, were assigned a different preference parameter value $\alpha$. We considered two different sets of possible values for the $\alpha$ s (see Table 1). In the First Set, the 30 values for the parameter were integer numbers selected from the interval $[0,70]$, while in the Second Set, the values were selected from the interval $[32,100] .^{2}$ Under the First Set of $\alpha$ values, as we can see from Table 1, the Nash equilibrium quantities requested by the subjects when charged according to the serial rule should be integer numbers from the interval $[0,19]$, while the Nash equilibrium quantities requested under the Second Set of $\alpha$ values are integer numbers in $[8,48] .{ }^{3}$ The use of these two sets of values for the subjects' preferences has allowed us to test the sensitivity of the serial cost sharing rule with respect to subjects demanding small versus large quantities.

Given the subjects' preferences, cost shares were calculated by the computer according to the serial cost sharing rule. Under the first treatment, in each period there were 4 rounds of quantities assignment, while in the second treatment quantities were assigned simultaneously. Under both treatments, the subjects had only information about their own earnings, their cost shares and the resulting profit corresponding to each quantity selected. Once the subjects made their choice and requested a particular quantity, under the simultaneous move treatment, they were informed of their final profit and led to the next period of play. Under the sequential treatment, on the other hand, after having selected a quantity, the subjects were informed whether the chosen quantity was the lowest quantity requested, in which case their final profit was also communicated; or whether their quantity was not the

\footnotetext{
${ }^{2}$ We added the Second Set of values, once we realized that when using preferences from the First Set, the application of a different cost sharing rule, such as the average cost sharing rule, would not have lead to the subjects demanding positive quantities. This problem does not arise when the preferences are selected from to the Second Set of Values.

${ }^{3} \mathrm{~A}$ t-test shows at the $1 \%$-level of significance that the two sets of values are different and that the average equilibrium strategy resulting from the First Set of preference parameters is on average significantly lower than the optimal strategy resulting from the Second Set of preference parameters.
} 
smallest quantity requested, in which case they were led to the next round. The players were allowed to choose any positive integer quantity, that is, their strategy space was the set of integer positive numbers. The subjects knew they were in a game, playing with computerized agents. They were also told that the computerized agents always behaved in such a way as to minimize the cost of the requested quantity, or to maximize their profit. A summary of all the experiments is reported in Table 2 .

\section{Experimental Results}

Results on the aggregate performance of the serial cost sharing rule are reported in Tables 3 through 8 .

Table 3 shows, for each of the 30 periods, the unique Nash equilibrium strategy, the average, minimum and maximum quantities requested by the subjects when the serial rule is implemented sequentially, and the preference parameters are drawn, respectively, from the First Set and the Second Set of values. Tables 4 provides, for the two sets of preference values with the serial rule implemented sequentially, the proportion of subjects choosing the Nash equilibrium strategy in each period (with deviations of plus and minus two units from the optimal quantity). ${ }^{4}$ Tables 5 and 6 present the same data for the other treatment, with the serial rule implemented as a simultaneous move game.

Tables 7 and 8 summarize the major findings characterizing the experiments, according to 1 ) the percentage of Nash Equilibrium play ${ }^{5}$; 2) the efficiency from the mechanism, measured as percentage of potential profit realized; and 3) the percentage of times that the subjects were assigned quantities in the correct ordering. The tables show this information for the two different treatments. For example, from the two tables we can see that out of 30 periods in each experiment, the unique Nash equilibrium strategy was chosen by a minimum of $38.67 \%$ of subjects (sequential treatment, Second Set of Values) to a maximum of $84.38 \%$ of subjects (sequential treatment, First Set of Values). On average subjects attained from a minimum $90.34 \%$ of the potential profit (simultaneous treatment, Second Set of Values) to $94.83 \%$ of the potential profit (sequential treatment, First Set of

\footnotetext{
${ }^{4}$ Given the shape of the profit function, deviations of plus or minus two units from the optimal quantity have almost no effect on total profit.

${ }^{5}$ With deviations of plus or minus two units from the optimal quantity.
} 
Values). Finally, the correct ordering of quantities provided was preserved from a minimum of $51 \%$ of the periods (sequential treatment, Second Set of Values), to over $89 \%$ of the times (sequential treatment, First Set of Values).

Examining the behavior of subjects during the periods of experiment, we see that in general their choices did not converge to the dominant strategy choice immediately. Even though the game induced by the serial cost sharing rule is dominance solvable and has a unique strong Nash equilibrium, the players took several iterations of the game to converge to it.

Figures 2 and 3 plot the differences between the Nash equilibrium quantity and the quantity actually chosen on average by the subjects in each period (with standard deviations of plus and minus one unit).

We can state the following results.

Result 1.A. (Proportion of Nash Equilibrium Play: Comparison between Treatments.) - The percentage of Nash Equilibrium play is significantly lower, under the Sequential Treatment.

Support. A z-test confirms at the 5\%-level of significance that the proportion of Nash Equilibrium play is higher under the Simultaneous Move treatment. Over all types of subjects, and all sets of preference parameters, the percentage of Nash equilibrium play under the sequential treatment is $73.49 \%$, while under the Simultaneous Move treatment it is $76.67 \%$ (one tailed z-test value is 1.76$)$.

Result 1.B. (Proportion of Nash Equilibrium Play: Comparison between Sets of Values). - Under both treatments, if values are drawn from the Second Set of Values, the percentage of Nash Equilibrium play is significantly decreased.

Support. Using the data provided in Tables 7 and 8 we can show that the proportion of Nash Equilibrium play is higher at the 1\%-level of significance when preferences are drawn from the First set of Values under both treatments (for the Simultaneous Move treatment the one-tailed z-test value is 5.81, while for the Sequential treatment the one-tailed z-test value is 15$)$.

Figures 4 and 5 show the percentage of subjects choosing a quantity "close" to the Nash equilibrium quantity, as a function of the subjects' optimal value. In Figure 4a and 4b, such percentages are shown for all possible values of the preference parameter under the two different treatments. The higher is the optimal Nash equilibrium quantity that the subjects should choose, the lower is the percentage of subjects that will choose correctly, as 
the downward sloping trend in Figure 4 reveals. Figures 5a, 5b, 5c and 5d show the same information, for the two different sets of preference parameter values. Under both treatments, the percentage of subjects not choosing the Nash equilibrium strategy is much higher under the Second Set of Values.

Result 2.A. (Efficiency: Comparison between Treatments. There is no significant difference between the two treatments in terms of efficiency, measured as percentage of potential profit actually realized.

Support. Using a z-test, at the 1\%-level of significance we cannot reject the hypothesis that for all values the percentages of potential profits realized under the two treatments are equal. Pulling all the values together (see Table 9), the percentage of potential profit realized by all subjects under the sequential treatment is $93.54 \%$, while the percentage realized under the simultaneous treatment is $90.76 \%$ (z-test values is 2.45 ).

Result 2.B. (Efficiency: Comparison between Sets of Values). Efficiency, as percentage of potential profit realized, under the Second Set of Values is not significantly different from the efficiency under the First Set of Values for the Simultanoeus Move treatment (1\% level of significance) and for the Sequential treatment (10\% level of significance).

Support. As indicated by the data shown in Table 10, for all treatments, at the $1 \%$-level of significance, the percentage of potential profit realized is not significantly different when preferences are drawn from the First Set of Values (93.74\% as compared to $91.19 \%$; one-tailed z-test value is 2.11 ).

In terms of efficiency, under both treatments, on average, subjects were able to gain more than $90 \%$ of the available surplus: $94.83 \%$ when the serial rule is implemented sequentially and $92 \%$ when it is implemented as a simultaneous move game for the First Set of values. If the preference parameters are drawn from the Second Set of values, the efficiency performance under the two treatments is reduced, but not significantly so.

Result 3.A. (Correct Order of Quantities: Comparison between Treatments). - The Simultaneous Move treatment does not perform significantly better than the Sequential implementation of the serial rule in terms of Correct Order of quantity, measured as the percentage of times that the correct order of quantities provided has been preserved in the realized allocation.

Support. Using a z-test, at the 1\%-level of significance we cannot reject the hypothesis that for all values, the percentage of times the correct order realizes under the two treatments is equal under the Simultaneous Move treatment when compared to the Sequential treatment. Pulling all the values 
together, the percentage of times the correct order realizes for all subjects under the Sequential treatment is $80.00 \%$, while the percentage realized under the Simultaneous treatment is $79.62 \%$ (one-tailed z-test value is 0.22 ).

Result 3.B. (Correct Order of Quantities: Comparison between Sets of Values). - The Correct Order of Quantity under the Second Set of Values is significantly lower (at the 1\%-level of significance) than the Correct Order of Quantities under the First Set of Values for both treatments.

Support. As the data shown in Table 9 indicates, for all treatments the percentage of times the correct order of quantities realizes is higher when preferences are drawn from the First Set of Values (88.78\% as compared to $61.20 \%$; one-tailed z-test value is 14.14).

Result 4. Learning. - Both treatments exhibit a significant amount of learning as subjects play over time. Mistakes are significantly lower as subjects become experienced, and under the Simultaneous Move treatment.

Support. We have estimated a linear least squares model using as dependent variable the absolute difference between the Nash Equilibrium quantity $\left(q^{*}\right)$ and the actual choice realized by the subjects $\left(q_{i}\right)$. The total number of observations is 2310. Estimates are reported in Table 10 below. Accounting for treatment (TREAT) and Set of Values (SET), the absolute difference between the Nash Equilibrium and the quantity chosen is significantly lower the higher is the period in which subjects are playing (as measured by the variable TIME). This represents strong evidence for a learning effect. The significant positive coefficient on the variable $q^{* 2}$ supports the conclusion that subjects' deviation from the optimal quantity increases the higher the value of this quantity. In addition, the absolute deviation is - ceteris paribus - slightly higher if the Sequential treatment is implemented. (Other variables: TREAT equals 0 for the Simultaneous Move treatment and 1 for the Sequential treatment, SET is equal to zero for the First Set of Values and 1 for the Second Set of Values.)

These results are consistent with Y. Chen's (1999) and Chen and Razzolini (2002) results on the incentive properties of the serial rule. Both papers compare the performance of the serial rule with the average cost pricing mechanism. Under complete information, ${ }^{6}$ the two mechanisms con-

\footnotetext{
${ }^{6}$ Under the complete information treatment, subjects have information about their own and their opponent's cost shares and profit for any quantity demanded.
} 
verge to the Nash equilibrium. Under limited information, ${ }^{7}$ however, the serial rule performs robustly better in terms of convergence to the Nash equilibrium allocation. The present experiment is similar to Chen's and Chen and Razzolini's limited information treatment, in the sense that our subject only have information about their own cost shares and payoffs. In the two previous studies, the subjects maintain their preference parameter throughout the entire experiment, while in our experiment, the subjects' preference parameter changes in each period. This implies that in each period the allocation mechanism must converge to a different Nash equilibrium allocation. In Chen's experiment, the subjects play for 150 periods and face only one opponent player, so that the strategic interaction among players is simplified. In Chen and Razzolini's experiment, there are 50 rounds of play and four types of players, with the most complicated scenario of possible strategic interactions among players. In our experiment, subjects face three computerized opponents, each with a different preference parameter. The use of computerized players allows us to desing a controlled environment in which to analyze the strategic properties of the serial rule independent on additional complications caused and induced by human interaction. Finally in our experiment, the subjects play only for 30 periods; that is, at most they get to choose a quantity for 120 times, if the sequential treatment is applied. Given all these differences, however, we confirm that while some learning is needed, the serial mechanism leads to almost efficient allocations.

\section{Conclusions}

This paper reports an experimental test of the equilibrium strategic properties of the serial cost sharing rule originally proposed by Shenker (1990) and then analyzed by Moulin and Shenker (1992). We brought subjects into an experimental laboratory and asked them to make decisions about the quantity of a common good they desire to acquire, given that costs are shared according to the serial cost sharing rule. We report measures of the performance and efficiency of the serial mechanism by comparing the choices and values attained by the subjects to the expected Nash equilibrium allocations.

We tested the rule using two different treatments: a simultaneous move application versus a sequential implementation of the serial rule. Even though easier to understand and implement, the simultaneous move treat-

\footnotetext{
${ }^{7}$ In this case, subjects have information only about their profit after requesting a quantity.
} 
ment's performance failed to be significantly different from the sequential implementation. The latter corresponds to the implementation of the the rule in dominant strategies. We also tested the rule using two different sets of preference parameter values: the higher the optimal quantity that subjects are supposed to demand, the worse is the performance of the serial rule. This follows from the fact that the search for the optimal quantity is conducted over a larger set.

In conclusion, experimental evidence shows that, learning is needed. However, while some learning is needed, the serial mechanism leads to almost efficient allocations. There are many examples of dominant strategy mechanisms which do not perform well in the experimental laboratory, in the sense that subjects fail to play their dominant strategy. The serial mechanism just confirms this finding: learning is necessary for the subjects to identify their dominant strategy.

\section{Bibliography}

Chen, Y., (forthcoming), "Asynchronicity and Learning in Cost Sharing Mechanisms," Journal of Public Economics.

Chen, Y. and Razzolini L., (2002), "An Experimental Study of Congestion and Cost Allocation Mechanisms for Distributed Networks," Manuscript, University of Michigan.

Deb, R. and Razzolini, L. (1999), "Voluntary Cost Sharing for an Excludable Public Project." Mathematical Social Sciences, 37, 123-138.

Deb, R. and Razzolini, L. (1999), "Auction Like Mechanisms for Pricing Excludable Public Goods." Journal of Economic Theory, 88, 340-368.

Gailmard S. and Palfrey T., (2001), "An Experimental Comparison of Collective Choice Procedures fro Excludable Public Goods," Manuscript. California Institute of Technology.

Moulin, H., (1994), "Serial Cost Sharing of Excludable Public Goods," Review of Economic Studies, 61, 305-325.

Moulin, H. and Shenker S., (1992), "Serial Cost Sharing," Econometrica, 60, 1009-1037.

Shenker S., (1990), "Making Greed Work in Networks: A Game-Theoretic Analysis of Gateway Service Disciplines," Mimeo, Xerox Palo Alto Research Center. 
Table 1 - Preference parameters and corresponding Nash equilibrium quantities

\begin{tabular}{|c|c|c|c|c|c|c|c|c|c|c|c|c|c|c|c|}
\hline \multicolumn{8}{|c|}{ 1st Set of Values } & \multicolumn{8}{|c|}{ 2nd Set of Values } \\
\hline$\alpha_{1}$ & $\alpha_{2}$ & $\alpha_{3}$ & $\alpha_{4}$ & $q_{1}$ & $q_{2}$ & $q_{3}$ & $q_{4}$ & $\alpha_{1}$ & $\alpha_{2}$ & $\alpha_{3}$ & $\alpha_{4}$ & $q_{1}$ & $q_{2}$ & $q_{3}$ & $q_{4}$ \\
\hline 34 & 0 & 35 & 6 & 16 & 0 & 17 & 2 & 95 & 81 & 72 & 85 & 33 & 21 & 18 & 23 \\
\hline 36 & 4 & 29 & 19 & 18 & 1 & 11 & 6 & 67 & 64 & 67 & 93 & 17 & 16 & 17 & 43 \\
\hline 29 & 16 & 33 & 25 & 9 & 4 & 13 & 7 & 77 & 52 & 58 & 70 & 28 & 13 & 15 & 21 \\
\hline 8 & 35 & 33 & 11 & 2 & 16 & 14 & 3 & 70 & 56 & 74 & 68 & 19 & 14 & 23 & 18 \\
\hline 9 & 23 & 3 & 0 & 4 & 18 & 1 & 0 & 78 & 70 & 66 & 60 & 27 & 19 & 17 & 15 \\
\hline 8 & 20 & 14 & 28 & 2 & 7 & 4 & 15 & 79 & 69 & 60 & 84 & 23 & 18 & 15 & 28 \\
\hline 43 & 48 & 12 & 39 & 14 & 19 & 3 & 12 & 54 & 48 & 70 & 56 & 14 & 12 & 29 & 15 \\
\hline 16 & 4 & 20 & 22 & 5 & 1 & 7 & 9 & 32 & 37 & 44 & 35 & 8 & 10 & 17 & 9 \\
\hline 22 & 24 & 16 & 4 & 8 & 10 & 5 & 1 & 84 & 89 & 64 & 76 & 24 & 29 & 16 & 20 \\
\hline 33 & 21 & 12 & 25 & 16 & 6 & 3 & 8 & 48 & 72 & 57 & 51 & 12 & 31 & 16 & 13 \\
\hline 64 & 58 & 62 & 52 & 19 & 15 & 17 & 13 & 99 & 64 & 79 & 73 & 42 & 16 & 22 & 19 \\
\hline 43 & 20 & 23 & 46 & 16 & 5 & 6 & 19 & 85 & 80 & 70 & 64 & 28 & 23 & 18 & 16 \\
\hline 19 & 22 & 9 & 0 & 8 & 11 & 3 & 0 & 61 & 52 & 85 & 55 & 17 & 13 & 41 & 14 \\
\hline 30 & 12 & 15 & 29 & 12 & 3 & 4 & 11 & 59 & 75 & 80 & 56 & 15 & 23 & 28 & 14 \\
\hline 37 & 24 & 27 & 44 & 12 & 6 & 7 & 19 & 65 & 60 & 84 & 63 & 17 & 15 & 36 & 16 \\
\hline 12 & 18 & 42 & 38 & 3 & 5 & 19 & 15 & 63 & 76 & 60 & 63 & 16 & 29 & 15 & 16 \\
\hline 8 & 26 & 40 & 43 & 2 & 8 & 15 & 18 & 39 & 35 & 32 & 45 & 11 & 9 & 8 & 17 \\
\hline 17 & 8 & 26 & 11 & 6 & 2 & 15 & 3 & 63 & 60 & 95 & 69 & 16 & 15 & 45 & 19 \\
\hline 47 & 8 & 49 & 35 & 17 & 2 & 19 & 11 & 55 & 52 & 89 & 55 & 14 & 13 & 48 & 14 \\
\hline 40 & 29 & 8 & 37 & 16 & 9 & 2 & 13 & 80 & 78 & 60 & 78 & 23 & 21 & 15 & 21 \\
\hline 12 & 18 & 20 & 22 & 3 & 5 & 6 & 8 & 100 & 80 & 72 & 78 & 41 & 21 & 18 & 20 \\
\hline 41 & 42 & 12 & 39 & 13 & 14 & 3 & 12 & 52 & 74 & 62 & 58 & 13 & 29 & 17 & 15 \\
\hline 8 & 41 & 14 & 38 & 2 & 19 & 4 & 16 & 42 & 40 & 38 & 32 & 13 & 11 & 10 & 8 \\
\hline 0 & 30 & 21 & 3 & 0 & 19 & 10 & 1 & 67 & 71 & 64 & 78 & 17 & 19 & 16 & 26 \\
\hline 37 & 15 & 0 & 33 & 18 & 5 & 0 & 14 & 68 & 72 & 56 & 74 & 18 & 20 & 14 & 22 \\
\hline 70 & 69 & 67 & 64 & 19 & 18 & 17 & 16 & 99 & 60 & 70 & 66 & 48 & 15 & 19 & 17 \\
\hline 35 & 33 & 12 & 37 & 11 & 10 & 3 & 13 & 51 & 48 & 80 & 57 & 13 & 12 & 39 & 16 \\
\hline 30 & 24 & 34 & 32 & 8 & 6 & 11 & 9 & 84 & 63 & 55 & 52 & 39 & 18 & 14 & 13 \\
\hline 59 & 60 & 44 & 53 & 17 & 18 & 11 & 14 & 73 & 64 & 95 & 79 & 19 & 16 & 38 & 22 \\
\hline 33 & 29 & 20 & 42 & 10 & 8 & 5 & 19 & 84 & 63 & 77 & 60 & 30 & 16 & 23 & 15 \\
\hline
\end{tabular}

Note: $\alpha_{1}$ is the human player's preference parameter. 
Table 2 - Features of Experimental Sessions

\begin{tabular}{ccccc}
\hline & Preference & $\#$ & \# Obser- & $\begin{array}{c}\text { Game Length } \\
\text { (periods) }\end{array}$ \\
Treatment & Parameter & Subjects & & \\
\hline & & & & \\
vequential & First Set & 32 & 960 & $30 / 4$ rounds \\
Sequential & Second Set & 10 & 300 & $30 / 4$ rounds \\
Simult. Move & First Set & 20 & 600 & 30 \\
Simult. Move & Second Set & 15 & 450 & 30 \\
& & & & \\
\hline
\end{tabular}


Table 3 - Sequential Treatment

\begin{tabular}{|c|c|c|c|c|c|c|c|c|}
\hline \multicolumn{4}{|c|}{ First Set of Values (32) } & \multicolumn{5}{|c|}{$\underline{\text { Second Set of Values (10) }}$} \\
\hline Period & $\begin{array}{c}\text { Nash Equil. } \\
\text { quantity }\end{array}$ & $\begin{array}{c}\text { Avg qt } \\
\text { requested }\end{array}$ & $\begin{array}{l}\text { Min qt } \\
\text { requested }\end{array}$ & $\begin{array}{l}\text { Max qt } \\
\text { requested }\end{array}$ & $\begin{array}{c}\text { Nash Equil. } \\
\text { quantity }\end{array}$ & $\begin{array}{l}\text { Avg qt } \\
\text { requested }\end{array}$ & $\begin{array}{c}\text { Min qt } \\
\text { requested }\end{array}$ & $\begin{array}{l}\text { Max qt } \\
\text { requested }\end{array}$ \\
\hline 1 & 16 & 12.9 & 4 & 24 & 33 & 20.4 & 10 & 30 \\
\hline 2 & 18 & 17 & 3 & 18 & 17 & 15.8 & 14 & 20 \\
\hline 3 & 9 & 8.2 & 3 & 17 & 28 & 18.3 & 15 & 20 \\
\hline 4 & 2 & 2.3 & 1 & 4 & 19 & 16.6 & 15 & 20 \\
\hline 5 & 4 & 4.1 & 1 & 10 & 27 & 17.1 & 10 & 20 \\
\hline 6 & 2 & 2.3 & 1 & 4 & 23 & 17.7 & 11 & 20 \\
\hline 7 & 14 & 12.4 & 3 & 15 & 14 & 11.8 & 9 & 14 \\
\hline 8 & 5 & 5 & 2 & 9 & 8 & 7.5 & 6 & 10 \\
\hline 9 & 8 & 7.7 & 2 & 12 & 24 & 18.8 & 10 & 22 \\
\hline 10 & 16 & 13.6 & 5 & 17 & 12 & 11.1 & 10 & 13 \\
\hline 11 & 19 & 16.1 & 0 & 17 & 42 & 21.8 & 10 & 25 \\
\hline 12 & 16 & 14.9 & 6 & 22 & 28 & 18.8 & 12 & 21 \\
\hline 13 & 8 & 7.8 & 2 & 16 & 17 & 14.3 & 12 & 20 \\
\hline 14 & 12 & 10.9 & 2 & 14 & 15 & 15.1 & 12 & 20 \\
\hline 15 & 12 & 11.2 & 4 & 15 & 17 & 15.7 & 10 & 20 \\
\hline 16 & 3 & 3.3 & 1 & 5 & 16 & 15.4 & 10 & 20 \\
\hline 17 & 2 & 2.4 & 1 & 4 & 11 & 9.5 & 8 & 11 \\
\hline 18 & 6 & 6 & 3 & 10 & 16 & 15.5 & 10 & 20 \\
\hline 19 & 17 & 15.9 & 5 & 19 & 14 & 12.9 & 10 & 15 \\
\hline 20 & 16 & 14.7 & 7 & 18 & 23 & 19 & 15 & 20 \\
\hline 21 & 3 & 3.6 & 3 & 6 & 41 & 23.2 & 20 & 30 \\
\hline 22 & 13 & 12.4 & 2 & 15 & 13 & 1.7 & 10 & 13 \\
\hline 23 & 2 & 2.1 & 1 & 3 & 13 & 10.1 & 9 & 12 \\
\hline 24 & 0 & 0.2 & 0 & 2 & 17 & 17.1 & 14 & 21 \\
\hline 25 & 18 & 16.1 & 6 & 19 & 18 & 17.3 & 14 & 21 \\
\hline 26 & 19 & 17.4 & 0 & 24 & 48 & 22.8 & 20 & 25 \\
\hline 27 & 11 & 10.9 & 5 & 14 & 13 & 11.5 & 9 & 13 \\
\hline 28 & 8 & 8.2 & 5 & 13 & 39 & 20.3 & 10 & 37 \\
\hline 29 & 17 & 16.7 & 6 & 23 & 19 & 18.3 & 13 & 21 \\
\hline 30 & 10 & 10 & 4 & 14 & 30 & 20.2 & 17 & 22 \\
\hline
\end{tabular}


Table 4 - Sequential Treatment, Nash Equilibrium Play

\begin{tabular}{|c|c|c|c|c|}
\hline \multirow[b]{2}{*}{ Period } & \multicolumn{2}{|c|}{$\underline{\text { First Set of Values }}$} & \multicolumn{2}{|c|}{$\underline{\text { Second Set of Values }}$} \\
\hline & $\begin{array}{c}\text { Nash } \\
\text { Equilibrium } \\
\text { Quantity }\end{array}$ & $\begin{array}{c}\text { \% Subjects (32) } \\
\text { choosing NE qt } \\
(+2,-2)\end{array}$ & $\begin{array}{c}\text { Nash } \\
\text { Equilibrium } \\
\text { Quantity }\end{array}$ & $\begin{array}{c}\% \text { Subjects }(10) \\
\text { choosing NE qt } \\
(+2,-2)\end{array}$ \\
\hline 1 & 16 & 53.1 & 33 & 0 \\
\hline 2 & 18 & 53.1 & 17 & 70 \\
\hline 3 & 9 & 78.1 & 28 & 0 \\
\hline 4 & 2 & 100 & 19 & 40 \\
\hline 5 & 4 & 87.5 & 27 & 0 \\
\hline 6 & 2 & 100 & 23 & 0 \\
\hline 7 & 14 & 78.1 & 14 & 50 \\
\hline 8 & 5 & 90.6 & 8 & 100 \\
\hline 9 & 8 & 87.5 & 24 & 10 \\
\hline 10 & 16 & 68.7 & 12 & 100 \\
\hline 11 & 19 & 59.4 & 42 & 0 \\
\hline 12 & 16 & 78.1 & 28 & 0 \\
\hline 13 & 8 & 78.1 & 17 & 30 \\
\hline 14 & 12 & 84.4 & 15 & 60 \\
\hline 15 & 12 & 81.2 & 17 & 40 \\
\hline 16 & 3 & 100 & 16 & 70 \\
\hline 17 & 2 & 100 & 11 & 70 \\
\hline 18 & 6 & 93.7 & 16 & 70 \\
\hline 19 & 17 & 81.2 & 14 & 80 \\
\hline 20 & 16 & 81.2 & 23 & 0 \\
\hline 21 & 3 & 93.7 & 41 & 0 \\
\hline 22 & 13 & 87.5 & 13 & 80 \\
\hline 23 & 2 & 100 & 13 & 20 \\
\hline 24 & 0 & 100 & 17 & 60 \\
\hline 25 & 18 & 75 & 18 & 60 \\
\hline 26 & 19 & 81.2 & 48 & 0 \\
\hline 27 & 11 & 84.4 & 13 & 70 \\
\hline 28 & 8 & 93.7 & 39 & 10 \\
\hline 29 & 17 & 90.6 & 19 & 70 \\
\hline 30 & 10 & 90.6 & 30 & 0 \\
\hline
\end{tabular}


Table 5 - Simultaneous Move Treatment

\begin{tabular}{|c|c|c|c|c|c|c|c|c|}
\hline \multicolumn{4}{|c|}{ First Set of Values (20) } & \multicolumn{5}{|c|}{ Second Set of Values (15) } \\
\hline Period & $\begin{array}{l}\text { Nash Equil. } \\
\text { quantity }\end{array}$ & $\begin{array}{l}\text { Avg qt } \\
\text { requested }\end{array}$ & $\begin{array}{l}\text { Min qt } \\
\text { requested }\end{array}$ & $\begin{array}{l}\text { Max qt } \\
\text { requested }\end{array}$ & $\begin{array}{l}\text { Nash Equil. } \\
\text { quantity }\end{array}$ & $\begin{array}{l}\text { Avg qt } \\
\text { requested }\end{array}$ & $\begin{array}{c}\text { Min } \mathrm{qt} \\
\text { requested }\end{array}$ & $\begin{array}{l}\text { Max qt } \\
\text { requested }\end{array}$ \\
\hline 1 & 16 & 13.9 & 3 & 16 & 33 & 23.6 & 2 & 33 \\
\hline 2 & 18 & 15.8 & 4 & 18 & 17 & 14.9 & 3 & 21 \\
\hline 3 & 9 & 8.3 & 4 & 9 & 28 & 21.3 & 4 & 30 \\
\hline 4 & 2 & 2.1 & 0 & 10 & 19 & 16.5 & 4 & 20 \\
\hline 5 & 4 & 3.9 & 1 & 5 & 27 & 21.2 & 4 & 30 \\
\hline 6 & 2 & 2 & 0 & 5 & 23 & 18.5 & 5 & 23 \\
\hline 7 & 14 & 12.6 & 3 & 14 & 14 & 12.5 & 5 & 14 \\
\hline 8 & 5 & 4.9 & 2 & 10 & 8 & 8.8 & 5 & 15 \\
\hline 9 & 8 & 7.4 & 1 & 15 & 24 & 18.5 & 3 & 24 \\
\hline 10 & 16 & 13.9 & 4 & 16 & 12 & 12 & 6 & 20 \\
\hline 11 & 19 & 16.1 & 2 & 19 & 42 & 31.5 & 6 & 42 \\
\hline 12 & 16 & 14 & 0 & 16 & 28 & 22.4 & 5 & 30 \\
\hline 13 & 8 & 7.8 & 1 & 15 & 17 & 14.7 & 5 & 20 \\
\hline 14 & 12 & 11.3 & 0 & 25 & 15 & 13.7 & 6 & 20 \\
\hline 15 & 12 & 10.4 & 1 & 12 & 17 & 15.3 & 6 & 20 \\
\hline 16 & 3 & 3.1 & 1 & 5 & 16 & 14.9 & 9 & 20 \\
\hline 17 & 2 & 2.2 & 1 & 5 & 11 & 11.2 & 7 & 14 \\
\hline 18 & 6 & 6.1 & 4 & 10 & 16 & 13.9 & 5 & 20 \\
\hline 19 & 17 & 15.9 & 3 & 17 & 17 & 12.8 & 6 & 16 \\
\hline 20 & 16 & 14 & 1 & 16 & 23 & 19.2 & 8 & 23 \\
\hline 21 & 3 & 3 & 1 & 5 & 41 & 31.5 & 9 & 41 \\
\hline 22 & 13 & 11.3 & 3 & 14 & 13 & 12.6 & 6 & 17 \\
\hline 23 & 2 & 2.2 & 1 & 5 & 13 & 12.3 & 9 & 14 \\
\hline 24 & 0 & 0.3 & 0 & 5 & 17 & 14.8 & 5 & 20 \\
\hline 25 & 18 & 16.1 & 4 & 18 & 18 & 16.6 & 8 & 20 \\
\hline 26 & 19 & 16.2 & 2 & 19 & 48 & 36.4 & 10 & 50 \\
\hline 27 & 11 & 9.9 & 4 & 11 & 13 & 12.6 & 8 & 15 \\
\hline 28 & 8 & 7.9 & 5 & 15 & 39 & 29.9 & 7 & 40 \\
\hline 29 & 17 & 14.8 & 3 & 17 & 19 & 16.9 & 10 & 20 \\
\hline 30 & 10 & 9.5 & 5 & 10 & 30 & 24.1 & 8 & 30 \\
\hline
\end{tabular}


Table 6 - Simultaneous Move Treatment, \% Nash Equilibrium Play

\begin{tabular}{|c|c|c|c|c|}
\hline \multirow[b]{2}{*}{ Period } & \multicolumn{2}{|c|}{$\underline{\text { First Set of Values }}$} & \multicolumn{2}{|c|}{ Second Set of Values } \\
\hline & $\begin{array}{l}\text { Nash } \\
\text { Equilibrium } \\
\text { Quantity }\end{array}$ & $\begin{array}{c}\text { \% Subjects (20) } \\
\text { choosing NE qt } \\
(+2,-2)\end{array}$ & $\begin{array}{c}\text { Nash } \\
\text { Equilibrium } \\
\text { Quantity }\end{array}$ & $\begin{array}{c}\text { \% Subjects (15) } \\
\text { choosing NE qt } \\
(+2,-2)\end{array}$ \\
\hline 1 & 16 & 80 & 33 & 53.3 \\
\hline 2 & 18 & 80 & 17 & 60 \\
\hline 3 & 9 & 80 & 28 & 60 \\
\hline 4 & 2 & 85 & 19 & 73.3 \\
\hline 5 & 4 & 95 & 27 & 60 \\
\hline 6 & 2 & 90 & 23 & 60 \\
\hline 7 & 14 & 80 & 14 & 73.3 \\
\hline 8 & 5 & 85 & 8 & 73.3 \\
\hline 9 & 8 & 80 & 24 & 60 \\
\hline 10 & 16 & 80 & 12 & 73.3 \\
\hline 11 & 19 & 80 & 42 & 66.7 \\
\hline 12 & 16 & 80 & 28 & 66.7 \\
\hline 13 & 8 & 85 & 17 & 60 \\
\hline 14 & 12 & 75 & 15 & 66.7 \\
\hline 15 & 12 & 80 & 17 & 66.7 \\
\hline 16 & 3 & 85 & 16 & 73.3 \\
\hline 17 & 2 & 90 & 11 & 86.7 \\
\hline 18 & 6 & 90 & 16 & 60 \\
\hline 19 & 17 & 85 & 14 & 80 \\
\hline 20 & 16 & 80 & 23 & 60 \\
\hline 21 & 3 & 90 & 41 & 66.7 \\
\hline 22 & 13 & 75 & 13 & 73.3 \\
\hline 23 & 2 & 90 & 13 & 80 \\
\hline 24 & 0 & 95 & 17 & 53.3 \\
\hline 25 & 18 & 85 & 18 & 80 \\
\hline 26 & 19 & 80 & 48 & 66.7 \\
\hline 27 & 11 & 80 & 13 & 80 \\
\hline 28 & 8 & 80 & 39 & 66.7 \\
\hline 29 & 17 & 80 & 19 & 66.7 \\
\hline 30 & 10 & 80 & 30 & 66.7 \\
\hline
\end{tabular}


Table 7 - Summary of Results: Sequential Treatment, all Values

\begin{tabular}{c|ccc}
\hline \multirow{2}{*}{$\begin{array}{c}\text { Proportion } \\
\text { of NE } \\
\text { Play }\end{array}$} & $\begin{array}{c}\text { Efficiency } \\
\text { from the } \\
\text { Mechanism }\end{array}$ & $\begin{array}{c}\text { Correct Ordering } \\
\text { Preserved } \\
\text { on Average }\end{array}$ \\
\hline $\begin{array}{c}\text { Sequential } \\
\text { Treatment } \\
\text { 1st Set of Values }\end{array}$ & $84.38 \%$ & $94.83 \%$ & $89.06 \%$ \\
\hline $\begin{array}{c}\text { Sequential } \\
\text { Treatment } \\
\text { 2nd Set of Values }\end{array}$ & $38.67 \%$ & $92.48 \%$ & $51.00 \%$
\end{tabular}

Table 8 - Summary of Results: Simultaneous Move Treatment, all Values

\begin{tabular}{c|ccc}
\hline & $\begin{array}{c}\text { Proportion } \\
\text { of NE } \\
\text { Play }\end{array}$ & $\begin{array}{c}\text { Efficiency } \\
\text { from the } \\
\text { Mechanism }\end{array}$ & $\begin{array}{c}\text { Correct Ordering } \\
\text { Preserved } \\
\text { on Average }\end{array}$ \\
\hline $\begin{array}{c}\text { Simult. Move } \\
\text { Treatment } \\
\text { 1st Set of Values }\end{array}$ & $83.33 \%$ & $92.00 \%$ & $88.33 \%$ \\
\hline $\begin{array}{c}\text { Simult. Move } \\
\text { Treatment } \\
\text { 2nd Set of Values }\end{array}$ & $67.78 \%$ & $90.34 \%$ & $68.00 \%$
\end{tabular}


Table 9 - Summary of Results: Sequential Treatment and Simultaneous Move Treatment, all Values

\begin{tabular}{c|ccc}
\hline & $\begin{array}{c}\text { Proportion } \\
\text { of NE } \\
\text { Play }\end{array}$ & $\begin{array}{c}\text { Efficiency } \\
\text { from the } \\
\text { Mechanism }\end{array}$ & $\begin{array}{c}\text { Correct Ordering } \\
\text { Preserved } \\
\text { on Average }\end{array}$ \\
\hline $\begin{array}{c}\text { Simult. Move } \\
\text { Treatment } \\
1 \text { st \& 2nd Set of Values }\end{array}$ & $76.67 \%$ & $90.76 \%$ & $79.62 \%$ \\
\hline $\begin{array}{c}\text { Sequential } \\
\text { Treatment }\end{array}$ & $73.49 \%$ & $93.53 \%$ & $80.00 \%$ \\
1 st \&2nd Set of Values & & &
\end{tabular}

Table 10 - Summary of Results: First and Second Sets of Values, all Treatments

\begin{tabular}{c|ccc}
\hline & $\begin{array}{c}\text { Proportion } \\
\text { of NE } \\
\text { Play }\end{array}$ & $\begin{array}{c}\text { Efficiency } \\
\text { from the } \\
\text { Mechanism }\end{array}$ & $\begin{array}{c}\text { Correct Ordering } \\
\text { Preserved } \\
\text { on Average }\end{array}$ \\
\hline $\begin{array}{c}\text { Simult. Move \& Sequent. } \\
\text { Treatment } \\
\text { 1st Set of Values }\end{array}$ & $83.97 \%$ & $93.74 \%$ & $88.78 \%$ \\
\hline $\begin{array}{c}\text { Simult. Move \& Sequent. } \\
\text { Treatment }\end{array}$ & $56.13 \%$ & $91.19 \%$ & $61.20 \%$ \\
2nd Set of Values & & &
\end{tabular}


Table 11 - Estimates of linear least squares models (Newey-West HAC standard errors and covariance estimators); dependent variable is the absolute difference between the Nash Equilibrium quantity and the quantity chosen $(n=2310)$

\begin{tabular}{cccc}
\hline & 1 & 2 & 3 \\
$\mathrm{C}$ & $0.793732^{*}$ & 0.39770 & 0.315444 \\
& $(0.408489)$ & $(0.460892)$ & $(0.443853)$ \\
$q^{* 2}$ & $0.007967^{* * *}$ & $0.008061^{* * *}$ & $0.007865 * * *$ \\
& $(0.000830)$ & $(0.000799)$ & $(0.000803)$ \\
TIME & $-0.036454^{*}$ & $-0.036758^{*}$ & $-0.036122^{*}$ \\
& $(0.020966)$ & $(0.020888)$ & $(0.020649)$ \\
TREAT & & $0.686127^{* * *}$ & $0.730588^{* *}$ \\
& & $(0.340702)$ & $(0.336759)$ \\
SET & & & 0.319156 \\
& & & $(0.319853)$ \\
Adjusted $\mathrm{R}^{2}$ & 0.352180 & 0.356131 & 0.356426 \\
F-Statistic & 628.6307 & 426.7108 & 320.6946
\end{tabular}

Note: Standard errors are in parentheses; asterisks indicate significance at the $1 \%(* * *), 5 \%(* *)$ and $10 \%(*)$ levels respectively. 